OPEN ACCESS

Edited by:

Pedro M. Fernández-Salguero, University of Extremadura, Spain

Reviewed by:

Kamalakannan Rajasekaran, Genentech Foundation, USA Joaquin Teixidó,

Consejo Superior Investigaciones Científicas, Spain

*Correspondence:

Gianluca Baldanzi gianluca.baldanzi@med.uniupo.it

Specialty section:

This article was submitted to Signaling,

a section of the journa Frontiers in Cell and Developmental Biology

Received: 27 August 2016 Accepted: 14 November 2016 Published: 29 November 2016

Citation: Baldanzi G, Bettio V, Malacarne V and Graziani A (2016) Diacylglycerol Kinases: Shaping Diacylglycerol and Phosphatidic Acid Gradients to Control Cell Polarity.

Front. Cell Dev. Biol. 4:140. doi: 10.3389/fcell.2016.00140

\section{Diacylglycerol Kinases: Shaping Diacylglycerol and Phosphatidic Acid Gradients to Control Cell Polarity}

\author{
Gianluca Baldanzi ${ }^{1,2 *}$, Valentina Bettio ${ }^{1,2}$, Valeria Malacarne ${ }^{1,3}$ and Andrea Graziani ${ }^{1,3}$ \\ ${ }^{1}$ Department of Translational Medicine, University of Piemonte Orientale, Novara, Italy, ${ }^{2}$ Institute for Research and Cure of \\ Autoimmune Diseases, Novara, Italy, ${ }^{3}$ Division of Experimental Oncology, School of Medicine, University Vita e Salute San \\ Raffaele, Milan, Italy
}

Diacylglycerol kinases (DGKs) terminate diacylglycerol (DAG) signaling and promote phosphatidic acid (PA) production. Isoform specific regulation of DGKs activity and localization allows DGKs to shape the DAG and PA gradients. The capacity of DGKs to constrain the areas of DAG signaling is exemplified by their role in defining the contact interface between $T$ cells and antigen presenting cells: the immune synapse. Upon $T$ cell receptor engagement, both DGK $\alpha$ and $\zeta$ metabolize DAG at the immune synapse thus constraining DAG signaling. Interestingly, their activity and localization are not fully redundant because DGKל activity metabolizes the bulk of DAG in the cell, whereas DGK $\alpha$ limits the DAG signaling area localizing specifically at the periphery of the immune synapse. When DGKs terminate DAG signaling, the local PA production defines a new signaling domain, where PA recruits and activates a second wave of effector proteins. The best-characterized example is the role of DGKs in protrusion elongation and cell migration. Indeed, upon growth factor stimulation, several DGK isoforms, such as $\alpha, \zeta$, and $\gamma$, are recruited and activated at the plasma membrane. Here, local PA production controls cell migration by finely modulating cytoskeletal remodeling and integrin recycling. Interestingly, DGK-produced PA also controls the localization and activity of key players in cell polarity such as aPKC, Par3, and integrin $\beta 1$. Thus, T cell polarization and directional migration may be just two instances of the general contribution of DGKs to the definition of cell polarity by local specification of membrane identity signaling.

Keywords: immune synapse, migration, lipid domain, cell polarity, localization

\section{MEMBRANE IDENTITY AND CELL POLARITY}

The compartmentalization of plasma membrane proteins is a common characteristic of eukaryotic cells and provides the base for the establishment of signaling domains (Spira et al., 2012). Local changes in lipid distribution also contribute to plasma membrane heterogeneity. However, the actual size and stability of lipid domains in cell membranes is still debatable (Carquin et al., 2016). The presence of specific lipids in different cellular compartments, including the plasma membrane, is required for the localized recruitment of effector proteins like actin regulators, protein kinases, and small GTPases (Lemmon, 2008).

The contribution of phosphoinositides (PIs) to cell organization has been extensively characterized; specific PIs play a major role in determining the subcellular identity of membranes 
(Di Paolo and De Camilli, 2006). The balance between Phosphatidylinositol-trisphosphate $\left(\mathrm{PI}_{3,4,5} \mathrm{P} 3\right.$ ) (Di Paolo and De Camilli, 2006; Lemmon, 2008; Sánchez-Madrid and Serrador, 2009) and Phosphatidylinositol-bisphosphate $\left(\mathrm{PI}_{4,5} \mathrm{P} 2\right)$ (Di Paolo and De Camilli, 2006; Sánchez-Madrid and Serrador, 2009) is specifically involved in the generation and maintenance of cell polarity in a variety of experimental systems. In migrating leukocytes as well as in Dictyostelium cells, a $\mathrm{PI}_{3,4,5} \mathrm{P} 3 \rightarrow \mathrm{PI}_{4,5} \mathrm{P} 2$ gradient identifies the leading edge of the cell compared to the uropod at the rear (Sánchez-Madrid and Serrador, 2009). Similarly, in neurons, $\mathrm{PI}_{3,4,5} \mathrm{P} 3$ is enriched at the tip of the growing axon (Shi et al., 2003). In apical/basal polarized epithelial cells, $\mathrm{PI}_{4,5} \mathrm{P} 2$ accumulates at the apical domain whereas the basolateral membranes are enriched in $\mathrm{PI}_{3,4,5} \mathrm{P} 3$ (GassamaDiagne et al., 2006). In all these cases, local lipid enrichment results from the spatial segregation of $\mathrm{PI}_{3,4,5} \mathrm{P} 3$ generation by PI3Ks and its metabolism by PTEN activity (Funamoto et al., 2002; Lacalle et al., 2004; Martin-Belmonte et al., 2007; Leslie et al., 2008). Once established, the uneven distribution of PIs promotes cell polarization by recruiting specific effectors.

Similar to $\mathrm{PI}_{3,4,5} \mathrm{P} 3$ and $\mathrm{PI}_{4,5} \mathrm{P} 2$, both $\mathrm{DAG}$ and $\mathrm{PA}$ are: (i) second messengers that recruit a set of interacting proteins (Mérida et al., 2008), (ii) kept in balance by the combined action of PA phosphatases and DGKs (Sakane et al., 2007) and (iii) enriched in specific domains of the plasma membrane where they recruit specific effectors.

In quiescent cells grown on bi-dimensional surfaces, PA is present in relevant amounts with prominent distribution at the free edges compared with that at cell-cell contacts (Nishioka et al., 2010). Further PA production by PLD and DGKs is observed upon receptor triggering, with highest levels at the nascent lamellipodia (Nishioka et al., 2010). Herein, PA binding proteins such as aPKC (Chianale et al., 2010; Rainero et al., 2014) or Nir2 (Kim et al., 2013), drive cytoskeletal remodeling and protrusion elongation. Similarly, PA participates in the recruitment of the Rac activator, DOCK1, during dorsal ruffle formation in fibroblasts (Sanematsu et al., 2013), as well as in the localization and activation of the Rac-RhoGAP complex during neurite outgrowth (Kurooka et al., 2011). Moreover, DAG is locally produced by the activity of extracellular regulated phospholipase $\mathrm{C}$ (PLC) on $\mathrm{PI}_{4,5} \mathrm{P} 2$ (Kadamur and Ross, 2013) and by the PA phosphatase activity at both the plasma membrane and in the intracellular organelles (Brindley et al., 2009). The resulting DAG production is essential to many biological systems such as the immune synapse, the neuronal synapse, and phagocytosis (Almena and Mérida, 2011).

PA and DAG gradients are somehow different in migrating cells. Indeed, low PA levels have been found at the leading edge of spontaneously migrating HeLa cells compared to those at the trailing edge (Ferraz-Nogueira et al., 2014), whereas DAG is symmetrically enriched at the front of migrating cells (Nishioka et al., 2008). Similarly, PA is strongly decreased at the apical domain of polarized epithelial cells, whereas DAG is lightly enriched (Gerl et al., 2012). These data demonstrate the existence of PA and DAG enriched domains that contribute to cellular asymmetry and thus suggest a putative role of DGKs in the control of cell polarity. Accordingly, while in E. coli DGK is a transmembrane protein that phosphorylates multiple lipids (Van Horn and Sanders, 2012), mammalian DGKs are soluble enzymes recruited on demand at specific cellular locations where they act on specific DAG pools (Kobayashi et al., 2007). The relevance of targeting to specific membrane domains is evidenced by the presence of multiple domains controlling membrane association, in the $\mathrm{N}$ terminal part of all DGKs, apart from DGKE (Mérida et al., 2008).

Here, we will discuss some well-characterized examples of the contribution of DGK activity to the generation and maintenance of lipid signaling domains in polarized cells.

\section{DGK $\alpha$ AND $\zeta$ AT THE IMMUNOLOGICAL SYNAPSE}

The contact zone between the $\mathrm{T}$ cell and the antigenpresenting cell (APC) is a specialized structure described as the immunological synapse (IS) (Monks et al., 1998; Grakoui et al., 1999). The IS has a well-defined spatial organization where supramolecular activation clusters (SMACs) are arranged in radial symmetry to form a "bull's eye" shape (Monks et al., 1998). The more distal zone (dSMAC) is CD45-enriched and is characterized by active actin movements resembling the sensory lamellipodia of epithelial cells (Dustin et al., 2010). This is followed by a peripheral zone (pSMAC) enriched in adhesion molecules such as LFA-1 (lymphocyte functionassociated antigen-1, integrin $\alpha \mathrm{L} \beta 2$ ), and VLA4 (Very Late Antigen-4, integrin $\alpha 4 \beta 1$ ) and the associated talin that resemble adhesive lamella (Mittelbrunn et al., 2004). In the central part (cSMAC), coactivators (e.g., CD28) and kinases (LCK, Fyn) are enriched, but endocytosis also occurs, resembling that in uropods of migrating cells. The cSMAC is also the site of secretion of cytokines, cytolytic agents, and exosomes into the synapse (Dustin, 2014).

Upon antigen stimulation, $\mathrm{T}$ cell receptor (TCR) microclusters form at the IS periphery and move toward the cSMAC where they encounter the endocytic sorting machinery and are internalized. IS formation drives the polarization of the entire $\mathrm{T}$ cell, with the translocation of the microtubule organizing center (MTOC) between the IS and the nucleus, and the establishment of the uropod, a membrane zone enriched in signaling molecules at the opposite end of the $\mathrm{T}$ cell (Serrador et al., 1999). Both IS formation and repositioning of the MTOC are key events during the killing of a cognate target cell by cytotoxic $\mathrm{T}$ lymphocytes (CTLs). Cytotoxic granules move along microtubules and the granule content is released between the CTL and the target cell, where perforin and granzymes co-operate to induce rapid death of the target cell by apoptosis (de Saint Basile et al., 2010).

Unstimulated T cells display uniform distribution of DAG at the plasma membrane, whereas after $\mathrm{T}$ cell activation, a DAG gradient is established at the center of the IS by the activity of TCR-activated PLC $\gamma$ (Spitaler et al., 2006) and by the combined action of PLD and PA-phosphatases (Mor et al., 2007). This DAG is essential for the recruitment of downstream DAGdependent effectors such as conventional PKC (cPKCs), PKD, 
and RasGRP1, which promote the downstream $\mathrm{T}$ cell responses (Spitaler et al., 2006). As recently reviewed by Merida et al., rapid DAG metabolism occurs at the IS (Mérida et al., 2015). Indeed both DGK $\alpha$ and DGK $\zeta$ are translocated to the proximal and distal poles of the T cell during IS formation (Joshi et al., 2013) and both DGK $\alpha$ and DGKל are recruited to the TCR complex (Gerl et al., 2012). Despite a substantial overlap in localization upon TCR triggering and their common function as negative regulators of TCR-downstream signaling (Zhong et al., 2003; Olenchock et al., 2006), the roles of DGK $\alpha$ and DGK $\zeta$ do not seem fully redundant. Indeed, TCR triggers DGKS phosphorylation on the myristoylated alanine-rich C-kinase substrate (MARKS) domain by PKC (Gharbi et al., 2011). Upon phosphorylation, DGK $\zeta$ spreads among the entire immunological synapse, where it contributes to DAG metabolism (Gharbi et al., 2011; Joshi et al., 2013). Conversely, DGK $\alpha$ is selectively recruited to the periphery of the IS in a PI3K $\delta$ dependent manner (Chauveau et al., 2014). Membrane-associated DGK $\alpha$ is phosphorylated on $\mathrm{Y}_{335}$ and is activated by $\mathrm{Lck}$ and $\mathrm{Ca}^{2+}$ with a timing that overlaps with PLC $\gamma$-phosphorylation (Sanjuán et al., 2001; Merino et al., 2008). In vitro experiments show that membrane-localized DGKa in T cells displays a substantial overlap with the F-actin ring surrounding the central DAG bulk, where DGK $\alpha$ plays a specific role in restricting the DAG domain. Indeed, in WT and DGK $\zeta^{-/-} \mathrm{T}$ cells, the DAG probe C1 $\delta$-GFP was localized within this F-actin ring, whereas in DGKa $\alpha^{-/}$cells, DAG distribution appeared substantially broader (Chauveau et al., 2014). Thus, DGK $\alpha$ contributes to polarity determination by constraining DAG accumulation into the $\mathrm{CSMAC}$, while DGK $\zeta$ plays a general function in reducing the intensity of TCR-downstream signaling (Chauveau et al., 2014).

The DGK $\alpha$-mediated shaping of DAG gradient at the immune synapse is required for $\mathrm{T}$ cell polarization as $\mathrm{DGK} \alpha^{-/-}$cells show partial impairment in TCR-promoted MTOC re-localization and polarized secretion (Quann et al., 2009; Alonso et al., 2011; Chauveau et al., 2014). Absence of DGK activity closely resembles $\mathrm{T}$ cell treatment with DAG analogs, such as phorbol esters, which completely abrogate MTOC reorientation toward the IS (Quann et al., 2009). The relevance of DGK $\alpha$ in T cell polarization is less evident when assayed in conjugates between antigen presenting B cells and Jurkat T cells. In these IS, DGK $\alpha$ inhibition does not perturb MTOC and F-actin polarization, but significantly affects DAG accumulation at the IS, suggesting that some polarization events also occur in the absence of localized DAG signaling (Ruffo et al., 2016). A striking example of the functional relevance of DGK $\alpha$ in the control of T cell polarization is the X-linked lymphoproliferative disease 1 (XLP1). XLP-1 is a primary immunodeficiency due to defects in signaling lymphocytic activation molecule (SLAM)-associated protein (SAP), an adaptor protein that modulates TCR-induced signaling. We have demonstrated that the SLAM-SAP signaling axis negatively regulates DGK $\alpha$ activity in $\mathrm{T}$ cells (Baldanzi et al., 2011a). In XLP-1 SAP is mutated or absent and results in constitutive DGK $\alpha$ activity that blunts the DAG dependent TCR signaling (Dustin et al., 2010). Interestingly, SAP deficient cells not only show partial impairment of TCR signaling, but also have specific defects in novel PKC (nPKC) recruitment at the
IS (Cannons et al., 2004, 2010a), thus reducing the IS stability ad effector functions (Cannons et al., 2010b; Zhao et al., 2012). These defects are due to excessive DGK $\alpha$ activity, as silencing or inhibiting DGKa in SAP deficient cells restores the correct level of DAG and its effectors at the IS and reestablishes MTOC polarization (Ruffo et al., 2016). Accordingly, inhibition of DGK $\alpha$ activity had no substantial effect on the killing of target cells by activated $\mathrm{CD}^{+}$lymphocytes whereas it enhances the weak effector function of SAP deficient lymphocytes (Chauveau et al., 2014; Ruffo et al., 2016).

These observations indicate that a signaling domain enriched in DAG is generated by the fine-tuning of localized production by PLC $\gamma$ and equally localized metabolism by DGK $\alpha$ (Mérida et al., 2015). As evidenced in Figure 1, fine regulation of DGK $\alpha$ activity plays a central role, with a small fraction recruited and activated by PI3K $\delta$ at the pSMAC (Chauveau et al., 2014), and the remaining enzyme activity is inhibited by SAP (Baldanzi et al., 2011a). The resulting spatial definition of DAG signaling drives $\mathrm{T}$ cell polarization by promoting the local recruitment of multiple PKC isoforms (Quann et al., 2011) that in turn organize molecular motors such as dynein at the IS and myosin II at the opposite cell end (Liu et al., 2013). Once established, T cell polarity is maintained by polarized vesicular trafficking toward the IS, where DGK $\alpha$ also plays a role. Indeed, DGK $\alpha$ is recruited to multivesicular bodies and to exosomes, and it promotes both the polarization of MVBs toward the IS and exosome secretion (Alonso et al., 2011).

Little is known about the function of DGKs in other types of immune synapses. In NK cells, DGKל silencing or treatment with DGK inhibitors enhances effector functions (Prinz et al., 2014; Yang et al., 2016), but it is currently unknown if this relates to a change in the DAG gradient or to an increased efficiency of the secretory pathways.

Notably, while the role of DGK $\alpha$ as a DAG-driven signaling terminator has been extensively investigated, whether and how PA production by DGKs at the IS affects TCR signaling is currently unknown. However, some cues suggest this possibility as PA production by DGK $\alpha$ and $\zeta$ is required for $\mathrm{T}$ cell development (Guo et al., 2008), whereas DGKל-generated PA promotes TLR-induced IL-12 production by negatively regulating the PI3K-AKT pathway (Liu et al., 2007). Moreover, $\mathrm{PA}$ is an allosteric activator of PLC $\gamma$ (Jones and Carpenter, 1993), suggesting that a PA-dependent feedback mechanism can amplify the magnitude of the signal. Future studies addressing the localization and function of DGKs-generated PA in lymphocytes should provide further insights into TCR signaling.

\section{DGKS IN DIRECTIONAL MIGRATION}

The leading edge of growth factor stimulated cells is another site of intense PIPs turnover, where PLC $\gamma$ is recruited to produce a local enrichment of DAG coupled to $\mathrm{Ca}^{2+}$ release triggered by inositol triphosphate (Piccolo et al., 2002; Mouneimne et al., 2004; Nishioka et al., 2008). We have demonstrated that upon growth factor or chemokine-mediated stimulation of epithelial cells, DGK $\alpha$ is activated and recruited to the plasma membrane, 

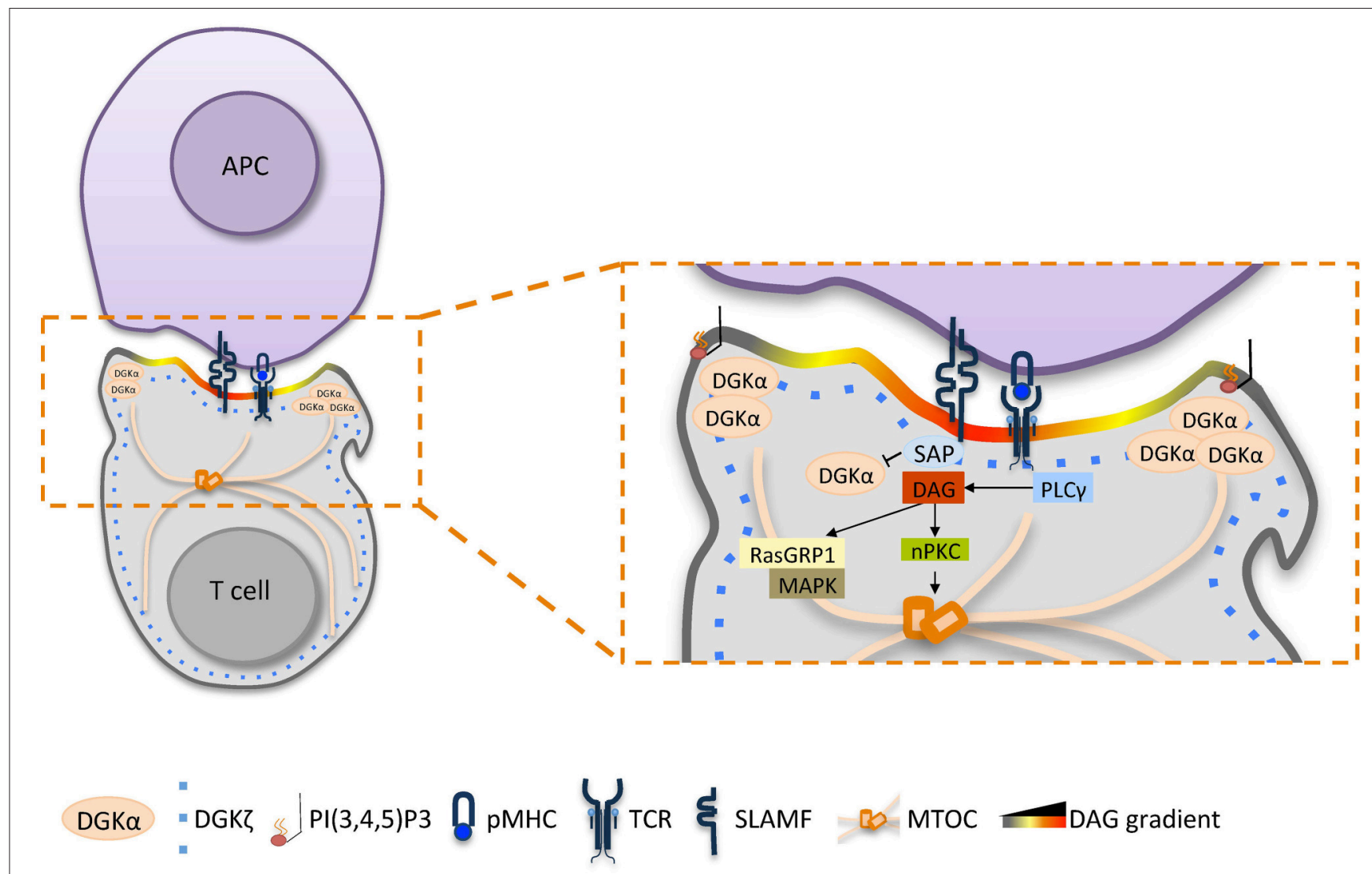

FIGURE 1 | The role of DGK $\alpha$ in shaping diacylglycerol signaling at the immune synapse. Upon TCR/SLAM engagement, PLC $\gamma$ activation induces DAG

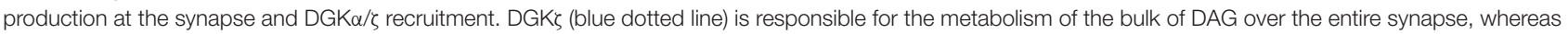
DGK $\alpha$ (light orange) is recruited by PI3K $\delta$ generated $\mathrm{Pl}_{3,4,5} \mathrm{P} 3$ at the pSMAC, where DAG is constrained. Excessive DAG metabolism at the IS by DGKa is prevented by SAP-mediated inhibition. The resulting sharp DAG gradient promotes downstream MAPK signaling and the local recruitment of nPKC, which promotes MTOC reorientation.

where the PA produced by DGK $\alpha$ recruits PA-binding proteins such as atypical PKC $\zeta$ and $\imath$ (aPKC $\zeta$; Chianale et al., 2007, 2010; Baldanzi et al., 2008) and Rab11 family interacting protein 1 (Rab11-FIP1) (Rainero et al., 2012). DGK $\alpha$ activated aPKC phosphorylates RhoGDI, thus promoting the release of Racl, actin polymerization, and elongation of invasive protrusions enriched in Integrin $\beta_{1}$ and metalloproteinase 9 (Chianale et al., 2007, 2010; Rainero et al., 2014). The PA produced by DGK $\alpha$ at the tip of invasive pseudopods is also a docking site for vesicles containing Rab11-FIP1 and Integrin $\alpha_{5} \beta_{1}$, allowing DGK $\alpha$ to polarize vesicular trafficking and promote directional migration (Rainero et al., 2014). Altogether, these data indicate that in epithelial cells, PA production by DGK $\alpha$ is essential to orchestrate the organization of the signaling machinery that promotes protrusion formation and directed cell migration (Figure 2A).

DGK $\alpha$ expression is low in mouse embryonic fibroblasts (MEFs), but other investigators have demonstrated that DGK $\zeta$ plays an equivalent role in cell migration. $\mathrm{DGK} \zeta^{-/-} \mathrm{MEFs}$ have more focal adhesions at their central region due to impairment in the local recruitment of PAK1 kinase. Upon PDGF

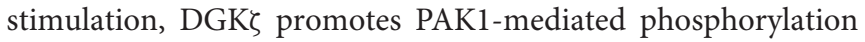

of RhoGDI that releases Rac1, which drives directed cell migration (Abramovici et al., 2009). Thus, close parallelism exists between the DGK $\alpha$ driven aPKC recruitment in epithelial cells and the DGK $\zeta$ mediated recruitment of PAK1 in MEFs, both controlling Rac1 activity and migration. Moreover, DGK $\zeta$ also regulates RhoA activity in MEFs by acting as a scaffolding protein independently of PA production (Ard et al., 2012). DGK $\zeta$ is also highly expressed in colon cancer cell lines and its expression correlates with enhanced cell motility due to increased Racl and RhoA activation (Cai et al., 2014), suggesting that DGK $\zeta$ is a key regulator of Rho GTPase activity and cell migration in fibroblasts and tumor cells (Figure 2B).

In fibroblasts, DGK $\gamma$ is also recruited to ruffles and lamellipodia where it co-localizes with Rac1 (Figure 2C). Surprisingly, DGK $\gamma$ acts as a suppressor of growth factorinduced protrusions by recruiting and activating the $\beta 2$-chimerin GAP activity (Tsushima et al., 2004; Yasuda et al., 2007). This observation clearly indicates the key contribution of DGKs to local PA accumulation that controls ruffling and lamellipodia formation (Nishioka et al., 2010), but suggests 
A
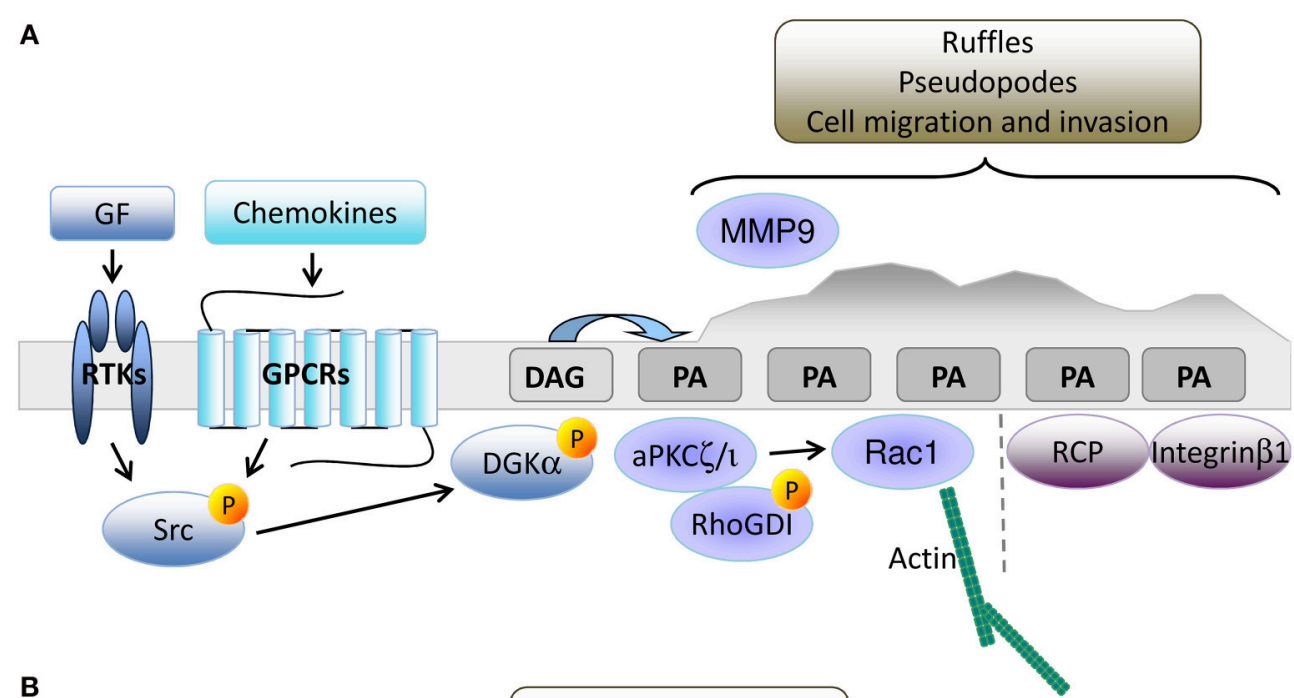

B

C
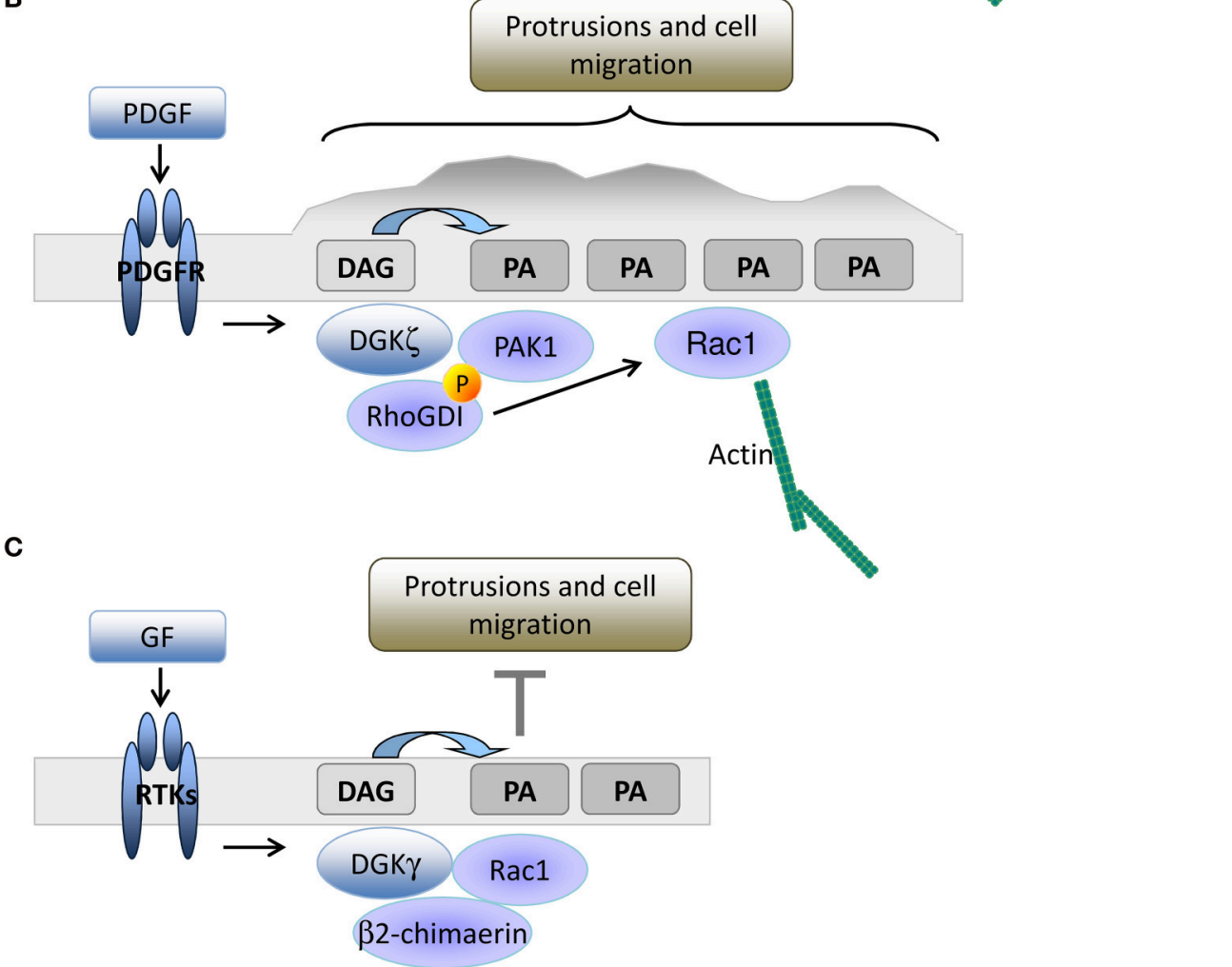

FIGURE 2 | DGKs-produced PA drives membrane protrusion and cell motility. (A) In epithelial cells, growth factors or chemokine stimulation promotes Src mediated recruitment and activation of DGKa to nascent protrusions. The resulting PA enriched domain drives protrusion elongation and matrix invasion by the local recruitment of aPKC and Rab11-FIP1. These PA binding proteins respectively control cytoskeletal remodeling through Rac1 and integrin $\beta 1$ recycling. (B) In fibroblasts, PDGF triggers DGKל recruitment to nascent protrusions. The resulting PA enriched domain drives focal adhesion remodeling and cell migration by recruiting and activating PAK1 and promoting Rac1 activation. (C) Growth factors also promote membrane recruitment and activation of DGK $\gamma$ that limits Rac1 activity through $\beta 2$ chimaerin.

that multiple PA pools with specific functions and interactors are involved. The relevance of protein-protein interactions in dictating the signaling outcome of DGK-produced PA is evidenced by the observation of the isoform specific complexes (i) DGK $\alpha$-aPKC-RhoGDI-Rac1 (Chianale et al., 2010), (ii)
DGK $\zeta$-PAK1-RhoGDI-Rac1 (Abramovici et al., 2009), and (iii) DGK $\gamma-\beta 2$ chimaerin (Yasuda et al., 2007).

The relevance of DAG and PA in cell migration suggests that DGKs are relevant targets for the control of tumor development and metastasis (Purow, 2015). Surprisingly, both DGK $\alpha$ and 
$\zeta$ also play a key role in cancer-cell survival, acting at either the plasma membrane, intracellular organelles, or the nucleus (Baldanzi et al., 2011b; Filigheddu et al., 2011; Dominguez et al., 2013; Kefas et al., 2013; Tanaka et al., 2013; Torres-Ayuso et al., 2014, 2015; Poli et al., 2016). However, the signaling pathways that converts PA and DAG at cell membranes in cell survival signaling are poorly understood, as few PA-regulated proteins are linked to the control of apoptosis and the cell cycle. Among these, mTOR (mammalian target of rapamycin) is notable as a target for both $\mathrm{PI}_{3,4,5} \mathrm{P} 3$ signaling and $\mathrm{DGK} \zeta$-produced $\mathrm{PA}$ (Avila-Flores et al., 2005; Chen et al., 2012; You et al., 2014).

\section{FUTURE PROSPECTS: DO DGKS PLAY A ROLE IN THE CONTROL OF CELL POLARITY?}

The illustrated data indicate the role of DGKs in the shaping of signaling domains at the plasma membrane by confining DAG signaling and contributing to the generation of PAenriched domains. In the $\mathrm{T}$ cells engaged in IS, the existence of a DAG gradient is necessary and sufficient to polarize the entire cytoskeleton (Quann et al., 2009) but the relevance of DAG gradients in other polarized systems such as front/rear or apical/basal asymmetry is currently under investigation (Tsai et al., 2014).

PA gradients are even less characterized because the relevance of PA in signaling is just emerging (Jang et al., 2012). A few studies found a role of PLD generated PA in the recruitment of PA binding proteins to the apical domain of epithelial monolayers (Gloerich et al., 2012; Consonni et al., 2014), despite controversial evidences about the apical enrichment of PA (Gerl et al., 2012). Interestingly, several data link the diacylglycerol generated-PA with central players in the establishment of cell polarity: aPKC, Par3, and integrin $\beta 1$ (Rainero et al., 2014). In apical/basal polarized epithelial cells, aPKC, Par3, and Par6 compose the Par complex, which is located at the apical side within the region of tight junctions, where it promotes the formation and maintenance of tight junctions and the apical domain (Horikoshi et al., 2009). Activation of aPKC is a key event in the regulation of apical/basal polarity since aPKC phosphorylates several substrates involved in polarity establishment such as Crumbs, Lgl, and GSK3 $\beta$ (glycogen synthase kinase-3 $\beta$ ). Phosphorylation of Crumbs and Lgl promotes their correct intracellular localization, whereas GSK3 $\beta$ phosphorylation is involved in microtubule capture and stabilization, and in the maturation of cell-cell contacts (Gandalovičová et al., 2016). The

\section{REFERENCES}

Abramovici, H., Mojtabaie, P., Parks, R. J., Zhong, X. P., Koretzky, G. A., Topham, M. K., et al. (2009). Diacylglycerol kinase zeta regulates actin cytoskeleton reorganization through dissociation of Rac1 from RhoGDI. Mol. Biol. Cell 20, 2049-2059. doi: 10.1091/mbc.E07-12-1248

Almena, M., and Mérida, I. (2011). Shaping up the membrane: diacylglycerol coordinates spatial orientation of signaling. Trends Biochem. Sci. 36, 593-603. doi: 10.1016/j.tibs.2011.06.005 link with DGKs is provided by the observation that: i) aPKC binds to and is activated by PA (Limatola et al., 1994) and ii) their localization at the invasive protrusions of cancer cells is promoted by DGK $\alpha$-produced PA (Chianale et al., 2010; Rainero et al., 2014). PA might also play a role in the localization of the aPKCPar3-Par6 complex as the Drosophila Par3 homolog, Bazooka also directly binds PA (Yu and Harris, 2012).

DGK $\alpha$-produced PA also controls intracellular trafficking of integrin $\beta 1$ through the PA binding protein Rab11-FIP1 (Lindsay and McCaffrey, 2004; Rainero et al., 2012). Interestingly, integrin $\beta 1$ trafficking is essential for directional migration (Shafaq-Zadah et al., 2016), apical/basal polarity (Bryant et al., 2014), and mitotic spindle orientation (Toyoshima and Nishida, 2007). Several evidences link integrin signaling and epithelial cell polarity (Zovein et al., 2010; Myllymäki et al., 2011), suggesting an interplay between integrin trafficking and Par complex activity. We speculate that DGKs-produced PA, which regulates both the Par complex through aPKC and integrin $\beta 1$ trafficking though Rab11-FIP1, contributes to the coordination of those pathways.

Starting from the observation of the central role of DGKs in establishing lymphocyte polarity and in directional migration, we propose that this family of enzymes may play a widespread role in the establishment of membrane domains that dictates cell polarization. The neuronal system is a very promising field to explore, where several DGK isoforms are expressed (Ishisaka and Hara, 2014) and control both neurite growth and branching (Shirai et al., 2010) and synapse stability (Kim et al., 2009; Shirai et al., 2010).

This review aims to prompt further studies investigating the link between DGKs activity, membrane asymmetry, and cell fate.

\section{AUTHOR CONTRIBUTIONS}

All authors listed, have made substantial, direct and intellectual contribution to the work, and approved it for publication.

\section{FUNDING}

AG is supported by grants from Telethon (GGP13254), AIRC (Associazione Italiana per la Ricerca sul Cancro) (IG13524) and PRIN (2015 4CWJH4). GB is supported by the TIPSO grant from Regione Piemonte (PAR FSC 2007-2013 Asse I-Innovazione e transizione produttiva-Linea di azione 3: "Competitività industria e artigianato" linea $\mathrm{d}$-Bando regionale sullemalattie Autoimmuni e Allergiche). Salary of VM and VB is provided by Telethon and TIPSO to AG and GB respectively. 
Avila-Flores, A., Santos, T., Rincón, E., and Mérida, I. (2005). Modulation of the mammalian target of rapamycin pathway by diacylglycerol kinase-produced phosphatidic acid. J. Biol. Chem. 280, 10091-10099. doi: 10.1074/jbc.M412296200

Baldanzi, G., Cutrupi, S., Chianale, F., Gnocchi, V., Rainero, E., Porporato, P., et al. (2008). Diacylglycerol kinase-alpha phosphorylation by Src on Y 335 is required for activation, membrane recruitment and Hgf-induced cell motility. Oncogene 27, 942-956. doi: 10.1038/sj.onc. 1210717

Baldanzi, G., Pietronave, S., Locarno, D., Merlin, S., Porporato, P., Chianale, F., et al. (2011b). Diacylglycerol kinases are essential for hepatocyte growth factordependent proliferation and motility of Kaposi's sarcoma cells. Cancer Sci. 102, 1329-1336. doi: 10.1111/j.1349-7006.2011.01953.x

Baldanzi, G., Pighini, A., Bettio, V., Rainero, E., Traini, S., Chianale, F., et al. (2011a). SAP-mediated inhibition of diacylglycerol kinase $\alpha$ regulates TCR-induced diacylglycerol signaling. J. Immunol. 187, 5941-5951. doi: 10.4049/jimmunol.1002476

Brindley, D. N., Pilquil, C., Sariahmetoglu, M., and Reue, K. (2009). Phosphatidate degradation: phosphatidate phosphatases (lipins) and lipid phosphate phosphatases. Biochim. Biophys. Acta 1791, 956-961. doi: 10.1016/j.bbalip.2009.02.007

Bryant, D. M., Roignot, J., Datta, A., Overeem, A. W., Kim, M., Yu, W., et al. (2014). A molecular switch for the orientation of epithelial cell polarization. Dev. Cell 31, 171-187. doi: 10.1016/j.devcel.2014.08.027

Cai, K., Mulatz, K., Ard, R., Nguyen, T., and Gee, S. H. (2014). Increased diacylglycerol kinase $\zeta$ expression in human metastatic colon cancer cells augments Rho GTPase activity and contributes to enhanced invasion. $B M C$ Cancer 14:208. doi: 10.1186/1471-2407-14-208

Cannons, J. L., Qi, H., Lu, K. T., Dutta, M., Gomez-Rodriguez, J., Cheng, J., et al. (2010b). Optimal germinal center responses require a multistage T cell:B cell adhesion process involving integrins, SLAM-associated protein, and CD84. Immunity 32, 253-265. doi: 10.1016/j.immuni.2010.01.010

Cannons, J. L., Wu, J. Z., Gomez-Rodriguez, J., Zhang, J., Dong, B., Liu, Y., et al. (2010a). Biochemical and genetic evidence for a SAP-PKC- $\theta$ interaction contributing to IL-4 regulation. J. Immunol. 185, 2819-2827. doi: $10.4049 /$ jimmunol.0902182

Cannons, J. L., Yu, L. J., Hill, B., Mijares, L. A., Dombroski, D., Nichols, K. E., et al. (2004). SAP regulates $\mathrm{T}(\mathrm{H}) 2$ differentiation and PKC- $\theta$-mediated activation of NF- $\kappa$ B1. Immunity 21, 693-706. doi: 10.1016/j.immuni.2004.09.012

Carquin, M., D’Auria, L., Pollet, H., Bongarzone, E. R., and Tyteca, D. (2016). Recent progress on lipid lateral heterogeneity in plasma membranes: from rafts to submicrometric domains. Prog. Lipid Res. 62, 1-24. doi: 10.1016/j.plipres.2015.12.004

Chauveau, A., A., Le Floc'h, Bantilan, N. S., Koretzky, G. A., and Huse, M. (2014). Diacylglycerol kinase $\alpha$ establishes $\mathrm{T}$ cell polarity by shaping diacylglycerol accumulation at the immunological synapse. Sci. Signal. 7, ra82. doi: 10.1126/scisignal.2005287

Chen, G., Chen, S. M., Wang, X., Ding, X. F., Ding, J., and Meng, L. H. (2012). Inhibition of chemokine (CXC motif) ligand 12/chemokine (CXC motif) receptor 4 axis (CXCL12/CXCR4)-mediated cell migration by targeting mammalian target of rapamycin (mTOR) pathway in human gastric carcinoma cells. J. Biol. Chem. 287, 12132-12141. doi: 10.1074/jbc.M111.302299

Chianale, F., Cutrupi, S., Rainero, E., Baldanzi, G., Porporato, P. E., Traini, S., et al. (2007). Diacylglycerol kinase-alpha mediates hepatocyte growth factor-induced epithelial cell scatter by regulating Rac activation and membrane ruffling. Mol. Biol. Cell 18, 4859-4871. doi: 10.1091/mbc.E07-02-0177

Chianale, F., Rainero, E., Cianflone, C., Bettio, V., Pighini, A., Porporato, P. E., et al. (2010). Diacylglycerol kinase alpha mediates HGF-induced Rac activation and membrane ruffling by regulating atypical PKC and RhoGDI. Proc. Natl. Acad. Sci. U.S.A. 107, 4182-4187. doi: 10.1073/pnas.0908326107

Consonni, S. V., Brouwer, P. M., van Slobbe, E. S., and Bos, J. L. (2014). The PDZ domain of the guanine nucleotide exchange factor PDZGEF directs binding to phosphatidic acid during brush border formation. PLoS ONE 9:e98253. doi: 10.1371/journal.pone.0098253

de Saint Basile, G., Ménasché, G., and Fischer, A. (2010). Molecular mechanisms of biogenesis and exocytosis of cytotoxic granules. Nat. Rev. Immunol. 10, 568-579. doi: 10.1038/nri2803

Di Paolo, G., and De Camilli, P. (2006). Phosphoinositides in cell regulation and membrane dynamics. Nature 443, 651-657. doi: 10.1038/nature05185
Dominguez, C. L., Floyd, D. H., Xiao, A., Mullins, G. R., Kefas, B. A., Xin, W., et al. (2013). Diacylglycerol kinase $\alpha$ is a critical signaling node and novel therapeutic target in glioblastoma and other cancers. Cancer Discov. 3, 782-797. doi: 10.1158/2159-8290.CD-12-0215

Dustin, M. L. (2014). The immunological synapse. Cancer Immunol. Res. 2, 1023-1033. doi: 10.1158/2326-6066.CIR-14-0161

Dustin, M. L., Chakraborty, A. K., and Shaw, A. S. (2010). Understanding the structure and function of the immunological synapse. Cold Spring Harb. Perspect. Biol. 2:a002311. doi: 10.1101/cshperspect.a002311

Ferraz-Nogueira, J. P., Díez-Guerra, F. J., and Llopis, J. (2014). Visualization of phosphatidic acid fluctuations in the plasma membrane of living cells. PLoS ONE 9:e102526. doi: 10.1371/journal.pone.0102526

Filigheddu, N., Sampietro, S., Chianale, F., Porporato, P. E., Gaggianesi, M., Gregnanin, I., et al. (2011). Diacylglycerol kinase $\alpha$ mediates $17-\beta$-estradiolinduced proliferation, motility, and anchorage-independent growth of Hec$1 \mathrm{~A}$ endometrial cancer cell line through the $\mathrm{G}$ protein-coupled estrogen receptor GPR30. Cell. Signal. 23, 1988-1996. doi: 10.1016/j.cellsig.2011. 07.009

Funamoto, S., Meili, R., Lee, S., Parry, L., and Firtel, R. A. (2002). Spatial and temporal regulation of 3-phosphoinositides by PI 3-kinase and PTEN mediates chemotaxis. Cell 109, 611-623. doi: 10.1016/S0092-8674(02)00755-9

Gandalovičová, A., Vomastek, T., Rosel, D., and Brábek, J. (2016). Cell polarity signaling in the plasticity of cancer cell invasiveness. Oncotarget 7 , 25022-25049. doi: 10.18632/oncotarget.7214

Gassama-Diagne, A., Yu, W., ter Beest, M., Martin-Belmonte, F., Kierbel, A., Engel, J., et al. (2006). Phosphatidylinositol-3,4,5-trisphosphate regulates the formation of the basolateral plasma membrane in epithelial cells. Nat. Cell Biol. 8, 963-970. doi: 10.1038/ncb1461

Gerl, M. J., Sampaio, J. L., Urban, S., Kalvodova, L., Verbavatz, J. M., Binnington, B., et al. (2012). Quantitative analysis of the lipidomes of the influenza virus envelope and MDCK cell apical membrane. J. Cell Biol. 196, 213-221. doi: $10.1083 /$ jcb. 201108175

Gharbi, S. I., Rincón, E., Avila-Flores, A., Torres-Ayuso, P., Almena, M., Cobos, M. A., et al. (2011). Diacylglycerol kinase $\zeta$ controls diacylglycerol metabolism at the immunological synapse. Mol. Biol. Cell 22, 4406-4414. doi: 10.1091/mbc.E11-03-0247

Gloerich, M., ten Klooster, J. P., Vliem, M. J., Koorman, T., Zwartkruis, F. J., Clevers, H., et al. (2012). Rap2A links intestinal cell polarity to brush border formation. Nat. Cell Biol. 14, 793-801. doi: 10.1038/ncb2537

Grakoui, A., Bromley, S. K., Sumen, C., Davis, M. M., Shaw, A. S., Allen, P. M., et al. (1999). The immunological synapse: a molecular machine controlling $\mathrm{T}$ cell activation. Science 285, 221-227. doi: 10.1126/science.285.5425.221

Guo, R., Wan, C. K., Carpenter, J. H., Mousallem, T., Boustany, R. M., Kuan, C. T., et al. (2008). Synergistic control of T cell development and tumor suppression by diacylglycerol kinase alpha and zeta. Proc. Natl. Acad. Sci. U.S.A. 105, 11909-11914. doi: 10.1073/pnas.0711856105

Horikoshi, Y., Suzuki, A., Yamanaka, T., Sasaki, K., Mizuno, K., Sawada, H. et al. (2009). Interaction between PAR-3 and the aPKC-PAR-6 complex is indispensable for apical domain development of epithelial cells. J. Cell Sci. 122(Pt 10), 1595-1606. doi: 10.1242/jcs.043174

Ishisaka, M., and Hara, H. (2014). The roles of diacylglycerol kinases in the central nervous system: review of genetic studies in mice. J. Pharmacol. Sci. 124, 336-343. doi: 10.1254/jphs.13R07CR

Jang, J. H., Lee, C. S., Hwang, D., and Ryu, S. H. (2012). Understanding of the roles of phospholipase $\mathrm{D}$ and phosphatidic acid through their binding partners. Prog. Lipid Res. 51, 71-81. doi: 10.1016/j.plipres.2011.12.003

Jones, G. A., and Carpenter, G. (1993). The regulation of phospholipase C- $\gamma 1$ by phosphatidic acid. Assessment of kinetic parameters. J. Biol. Chem. 268, 20845-20850.

Joshi, R. P., Schmidt, A. M., Das, J., Pytel, D., Riese, M. J., Lester, M., et al. (2013). The $\zeta$ isoform of diacylglycerol kinase plays a predominant role in regulatory T cell development and TCR-mediated ras signaling. Sci. Signal. 6, ra102. doi: 10.1126/scisignal.2004373

Kadamur, G., and Ross, E. M. (2013). Mammalian phospholipase C. Annu. Rev. Physiol. 75, 127-154. doi: 10.1146/annurev-physiol-030212-183750

Kefas, B., Floyd, D. H., Comeau, L., Frisbee, A., Dominguez, C., Dipierro, C. G., et al. (2013). A miR-297/hypoxia/DGK- $\alpha$ axis regulating glioblastoma survival. Neuro Oncol. 15, 1652-1663. doi: 10.1093/neuonc/not118 
Kim, K., Yang, J., Zhong, X. P., Kim, M. H., Kim, Y. S., Lee, H. W., et al. (2009). Synaptic removal of diacylglycerol by DGKzeta and PSD-95 regulates dendritic spine maintenance. EMBO J. 28, 1170-1179. doi: 10.1038/emboj. 2009.44

Kim, S., Kedan, A., Marom, M., Gavert, N., Keinan, O., Selitrennik, M., et al. (2013). The phosphatidylinositol-transfer protein Nir2 binds phosphatidic acid and positively regulates phosphoinositide signalling. EMBO Rep. 14, 891-899. doi: 10.1038/embor.2013.113

Kobayashi, N., Hozumi, Y., Ito, T., Hosoya, T., Kondo, H., and Goto, K. (2007). Differential subcellular targeting and activity-dependent subcellular localization of diacylglycerol kinase isozymes in transfected cells. Eur. J. Cell Biol. 86, 433-444. doi: 10.1016/j.ejcb.2007.05.002

Kurooka, T., Yamamoto, Y., Takai, Y., and Sakisaka, T. (2011). Dual regulation of RA-RhoGAP activity by phosphatidic acid and Rap1 during neurite outgrowth. J. Biol. Chem. 286, 6832-6843. doi: 10.1074/jbc.M110.183772

Lacalle, R. A., Gómez-Moutón, C., Barber, D. F., Jiménez-Baranda, S., Mira, E., C., et al. (2004). PTEN regulates motility but not directionality during leukocyte chemotaxis. J. Cell Sci. 117(Pt 25), 6207-6215. doi: 10.1242/ jcs. 01545

Lemmon, M. A. (2008). Membrane recognition by phospholipid-binding domains. Nat. Rev. Mol. Cell Biol. 9, 99-111. doi: 10.1038/nrm2328

Leslie, N. R., Batty, I. H., Maccario, H., Davidson, L., and Downes, C. P. (2008). Understanding PTEN regulation: PIP2, polarity and protein stability. Oncogene 27, 5464-5476. doi: 10.1038/onc.2008.243

Limatola, C., Schaap, D., Moolenaar, W. H., and van Blitterswijk, W. J. (1994). Phosphatidic acid activation of protein kinase C-zeta overexpressed in COS cells: comparison with other protein kinase $\mathrm{C}$ isotypes and other acidic lipids. Biochem. J. 304 (Pt 3), 1001-1008. doi: 10.1042/bj3041001

Lindsay, A. J., and McCaffrey, M. W. (2004). The C2 domains of the class I Rab11 family of interacting proteins target recycling vesicles to the plasma membrane. J. Cell Sci. 117(Pt 19), 4365-4375. doi: 10.1242/jcs.01280

Liu, C. H., Machado, F. S., Guo, R., Nichols, K. E., Burks, A. W., Aliberti, J. C., et al. (2007). Diacylglycerol kinase zeta regulates microbial recognition and host resistance to Toxoplasma gondii. J. Exp. Med. 204, 781-792. doi: $10.1084 /$ jem. 20061856

Liu, X., Kapoor, T. M., Chen, J. K., and Huse, M. (2013). Diacylglycerol promotes centrosome polarization in $\mathrm{T}$ cells via reciprocal localization of dynein and myosin II. Proc. Natl. Acad. Sci. U.S.A. 110, 11976-11981. doi: $10.1073 /$ pnas. 1306180110

Martin-Belmonte, F., Gassama, A., Datta, A., Yu, W., Rescher, U., Gerke, V., et al. (2007). PTEN-mediated apical segregation of phosphoinositides controls epithelial morphogenesis through Cdc42. Cell 128, 383-397. doi: 10.1016/j.cell.2006.11.051

Mérida, I., Andrada, E., Gharbi, S. I., and Ávila-Flores, A. (2015). Redundant and specialized roles for diacylglycerol kinases $\alpha$ and $\zeta$ in the control of T cell functions. Sci. Signal. 8, re6. doi: 10.1126/scisignal.aaa0974

Mérida, I., Avila-Flores, A., and Merino, E. (2008). Diacylglycerol kinases: at the hub of cell signalling. Biochem. J. 409, 1-18. doi: 10.1042/BJ20071040

Merino, E., Avila-Flores, A., Shirai, Y., Moraga, I., Saito, N., and Mérida, I. (2008). Lck-dependent tyrosine phosphorylation of diacylglycerol kinase alpha regulates its membrane association in T cells. J. Immunol. 180, 5805-5815. doi: 10.4049/jimmunol.180.9.5805

Mittelbrunn, M., Molina, A., Escribese, M. M., Yá-ez, M. Ó. M., Escudero, E., Yáñez-Mó, M., et al. (2004). VLA-4 integrin concentrates at the peripheral supramolecular activation complex of the immune synapse and drives T helper 1 responses. Proc. Natl. Acad. Sci. U.S.A. 101, 11058-11063. doi: 10.1073/pnas.0307927101

Monks, C. R., Freiberg, B. A., Kupfer, H., Sciaky, N., and Kupfer, A. (1998). Threedimensional segregation of supramolecular activation clusters in T cells. Nature 395, 82-86. doi: 10.1038/25764

Mor, A., Campi, G., Du, G., Zheng, Y., Foster, D. A., Dustin, M. L., et al. (2007). The lymphocyte function-associated antigen-1 receptor costimulates plasma membrane Ras via phospholipase D2. Nat. Cell Biol. 9, 713-719. doi: $10.1038 /$ ncb1592

Mouneimne, G., Soon, L., DesMarais, V., Sidani, M., Song, X., Yip, S. C., et al. (2004). Phospholipase $C$ and cofilin are required for carcinoma cell directionality in response to EGF stimulation. J. Cell Biol. 166, 697-708. doi: $10.1083 /$ jcb. 200405156
Myllymäki, S. M., Teräväinen, T. P., and Manninen, A. (2011). Two distinct integrin-mediated mechanisms contribute to apical lumen formation in epithelial cells. PLoS ONE 6:e19453. doi: 10.1371/journal.pone.0019453

Nishioka, T., Aoki, K., Hikake, K., Yoshizaki, H., Kiyokawa, E., and Matsuda, M. (2008). Rapid turnover rate of phosphoinositides at the front of migrating MDCK cells. Mol. Biol. Cell 19, 4213-4223. doi: 10.1091/mbc.E08-03-0315

Nishioka, T., Frohman, M. A., Matsuda, M., and Kiyokawa, E. (2010). Heterogeneity of phosphatidic acid levels and distribution at the plasma membrane in living cells as visualized by a Föster resonance energy transfer (FRET) biosensor. J. Biol. Chem. 285, 35979-35987. doi: 10.1074/jbc.M110.153007

Olenchock, B. A., Guo, R., Carpenter, J. H., Jordan, M., Topham, M. K., Koretzky, G. A., et al. (2006). Disruption of diacylglycerol metabolism impairs the induction of T cell anergy. Nat. Immunol. 7, 1174-1181. doi: 10.1038/ni1400

Piccolo, E., Innominato, P. F., Mariggio, M. A., Maffucci, T., Iacobelli, S., and Falasca, M. (2002). The mechanism involved in the regulation of phospholipase C $\gamma 1$ activity in cell migration. Oncogene 21, 6520-6529. doi: 10.1038/si.onc.1205821

Poli, A., Fiume, R., Baldanzi, G., Capello, D., Ratti, S., Gesi, M., et al. (2016). Nuclear localization of diacylglycerol kinase Alpha in K562 cells is involved in cell cycle progression. J. Cell. Physiol. doi: 10.1002/jcp.25642. [Epub ahead of print].

Prinz, P. U., Mendler, A. N., Brech, D., Masouris, I., Oberneder, R., and Noessner, E. (2014). NK-cell dysfunction in human renal carcinoma reveals diacylglycerol kinase as key regulator and target for therapeutic intervention. Int. J. Cancer 135, 1832-1841. doi: $10.1002 /$ ijc. 28837

Purow, B. (2015). Molecular pathways: targeting diacylglycerol kinase alpha in cancer. Clin. Cancer Res. 21, 5008-5012. doi: 10.1158/1078-0432.CCR$15-0413$

Quann, E. J., Liu, X., Altan-Bonnet, G., and Huse, M. (2011). A cascade of protein kinase $\mathrm{C}$ isozymes promotes cytoskeletal polarization in T cells. Nat. Immunol. 12, 647-654. doi: 10.1038/ni.2033

Quann, E. J., Merino, E., Furuta, T., and Huse, M. (2009). Localized diacylglycerol drives the polarization of the microtubule-organizing center in T cells. Nat. Immunol. 10, 627-635. doi: 10.1038/ni.1734

Rainero, E., Caswell, P. T., Muller, P. A., Grindlay, J., McCaffrey, M. W. Zhang, Q., et al. (2012). Diacylglycerol kinase $\alpha$ controls RCP-dependent integrin trafficking to promote invasive migration. J. Cell Biol. 196, 277-295. doi: $10.1083 /$ jcb.201109112

Rainero, E., Cianflone, C., Porporato, P. E., Chianale, F., Malacarne, V., Bettio, V., et al. (2014). The diacylglycerol kinase $\alpha /$ atypical $P K C / \beta 1$ integrin pathway in SDF-1 $\alpha$ mammary carcinoma invasiveness. PLoS ONE 9:e97144. doi: 10.1371/journal.pone.0097144

Ruffo, E., Malacarne, V., Larsen, S. E., Das, R., Patrussi, L., Wülfing, C., et al. (2016). Inhibition of diacylglycerol kinase $\alpha$ restores restimulation-induced cell death and reduces immunopathology in XLP-1. Sci. Transl. Med. 8, 321 ra7. doi: 10.1126/scitranslmed.aad1565

Sakane, F., Imai, S., Kai, M., Yasuda, S., and Kanoh, H. (2007). Diacylglycerol kinases: why so many of them? Biochim. Biophys. Acta 1771, 793-806. doi: 10.1016/j.bbalip.2007.04.006

Sánchez-Madrid, F., and Serrador, J. M. (2009). Bringing up the rear: defining the roles of the uropod. Nat. Rev. Mol. Cell Biol. 10, 353-359. doi: 10.1038/nrm2680

Sanematsu, F., Nishikimi, A., Watanabe, M., Hongu, T., Tanaka, Y., Kanaho, Y., et al. (2013). Phosphatidic acid-dependent recruitment and function of the Rac activator DOCK1 during dorsal ruffle formation. J. Biol. Chem. 288, 8092-8100. doi: $10.1074 / j b c . M 112.410423$

Sanjuán, M. A., Jones, D. R., Izquierdo, M., and Mérida, I. (2001). Role of diacylglycerol kinase alpha in the attenuation of receptor signaling. J. Cell Biol. 153, 207-220. doi: 10.1083/jcb.153.1.207

Serrador, J. M., Nieto, M., and Sánchez-Madrid, F. (1999). Cytoskeletal rearrangement during migration and activation of T lymphocytes. Trends Cell Biol. 9, 228-233. doi: 10.1016/S0962-8924(99)01553-6

Shafaq-Zadah, M., Gomes-Santos, C. S., Bardin, S., Maiuri, P., Maurin, M., Iranzo, J., et al. (2016). Persistent cell migration and adhesion rely on retrograde transport of $\beta(1)$ integrin. Nat. Cell Biol. 18, 54-64. doi: 10.1038/ncb3287

Shi, S. H., Jan, L. Y., and Jan, Y. N. (2003). Hippocampal neuronal polarity specified by spatially localized mPar3/mPar6 and PI 3-kinase activity. Cell 112, 63-75. doi: 10.1016/S0092-8674(02)01249-7 
Shirai, Y., Kouzuki, T., Kakefuda, K., Moriguchi, S., Oyagi, A., Horie, K., et al. (2010). Essential role of neuron-enriched diacylglycerol kinase (DGK), DGKbeta in neurite spine formation, contributing to cognitive function. PLoS ONE 5:e11602. doi: 10.1371/journal.pone. 0011602

Spira, F., Mueller, N. S., Beck, G., von Olshausen, P., Beig, J., and Wedlich-Söldner, R. (2012). Patchwork organization of the yeast plasma membrane into numerous coexisting domains. Nat. Cell Biol. 14, 640-648. doi: $10.1038 / \mathrm{ncb} 2487$

Spitaler, M., Emslie, E., Wood, C. D., and Cantrell, D. (2006). Diacylglycerol and protein kinase D localization during $\mathrm{T}$ lymphocyte activation. Immunity 24 , 535-546. doi: 10.1016/j.immuni.2006.02.013

Tanaka, T., Okada, M., Hozumi, Y., Tachibana, K., Kitanaka, C., Hamamoto, Y., et al. (2013). Cytoplasmic localization of DGKל exerts a protective effect against p53-mediated cytotoxicity. J. Cell Sci. 126(Pt 13), 2785-2797. doi: $10.1242 /$ jcs. 118711

Torres-Ayuso, P., Daza-Martín, M., Martín-Pérez, J., Ávila-Flores, A., and Mérida, I. (2014). Diacylglycerol kinase $\alpha$ promotes 3D cancer cell growth and limits drug sensitivity through functional interaction with Src. Oncotarget 5 , 9710-9726. doi: 10.18632/oncotarget.2344

Torres-Ayuso, P., Tello-Lafoz, M., Mérida, I., and Ávila-Flores, A. (2015). Diacylglycerol kinase- $\zeta$ regulates mTORC1 and lipogenic metabolism in cancer cells through SREBP-1. Oncogenesis 4, e164. doi: 10.1038/oncsis. 2015.22

Toyoshima, F., and Nishida, E. (2007). Integrin-mediated adhesion orients the spindle parallel to the substratum in an EB1- and myosin X-dependent manner. EMBO J. 26, 1487-1498. doi: 10.1038/si.emboj.7601599

Tsai, F. C., Seki, A., Yang, H. W., Hayer, A., Carrasco, S., Malmersjö, S., et al. (2014). A polarized Ca2+, diacylglycerol and STIM1 signalling system regulates directed cell migration. Nat. Cell Biol. 16, 133-144. doi: 10.1038/ ncb2906

Tsushima, S., Kai, M., Yamada, K., Imai, S., Houkin, K., Kanoh, H., et al. (2004). Diacylglycerol kinase gamma serves as an upstream suppressor of Racl and lamellipodium formation. J. Biol. Chem. 279, 28603-28613. doi: 10.1074/jbc.M314031200

Van Horn, W. D., and Sanders, C. R. (2012). Prokaryotic diacylglycerol kinase and undecaprenol kinase. Annu. Rev. Biophys. 41, 81-101. doi: 10.1146/annurev-biophys-050511-102330
Yang, E., Singh, B. K., Paustian, A. M., and Kambayashi, T. (2016). Diacylglycerol kinase $\zeta$ is a target to enhance NK cell function. J. Immunol. 197, 934-941. doi: 10.4049/jimmunol.1600581

Yasuda, S., Kai, M., Imai, S., Kanoh, H., and Sakane, F. (2007). Diacylglycerol kinase gamma interacts with and activates beta2-chimaerin, a Rac-specific GAP, in response to epidermal growth factor. FEBS Lett. 581, 551-557. doi: 10.1016/j.febslet.2007.01.022

You, J. S., Lincoln, H. C., Kim, C. R., Frey, J. W., Goodman, C. A., Zhong, X. P., et al. (2014). The role of diacylglycerol kinase $\zeta$ and phosphatidic acid in the mechanical activation of mammalian target of rapamycin (mTOR) signaling and skeletal muscle hypertrophy. J. Biol. Chem. 289, 1551-1563. doi: $10.1074 /$ jbc.M113.531392

Yu, C. G., and Harris, T. J. (2012). Interactions between the PDZ domains of Bazooka (Par-3) and phosphatidic acid: in vitro characterization and role in epithelial development. Mol. Biol. Cell 23, 3743-3753. doi: 10.1091/mbc.E12-03-0196

Zhao, F., Cannons, J. L., Dutta, M., Griffiths, G. M., and Schwartzberg, P. L. (2012). Positive and negative signaling through SLAM receptors regulate synapse organization and thresholds of cytolysis. Immunity 36, 1003-1016. doi: 10.1016/j.immuni.2012.05.017

Zhong, X. P., Hainey, E. A., Olenchock, B. A., Jordan, M. S., Maltzman, J. S., Nichols, K. E., et al. (2003). Enhanced T cell responses due to diacylglycerol kinase zeta deficiency. Nat. Immunol. 4, 882-890. doi: 10.1038/ni958

Zovein, A. C., Luque, A., Turlo, K. A., Hofmann, J. J., Yee, K. M., Becker, M. S., et al. (2010). Betal integrin establishes endothelial cell polarity and arteriolar lumen formation via a Par3-dependent mechanism. Dev. Cell 18, 39-51. doi: 10.1016/j.devcel.2009.12.006

Conflict of Interest Statement: The authors declare that the research was conducted in the absence of any commercial or financial relationships that could be construed as a potential conflict of interest.

Copyright $\odot 2016$ Baldanzi, Bettio, Malacarne and Graziani. This is an open-access article distributed under the terms of the Creative Commons Attribution License (CC BY). The use, distribution or reproduction in other forums is permitted, provided the original author(s) or licensor are credited and that the original publication in this journal is cited, in accordance with accepted academic practice. No use, distribution or reproduction is permitted which does not comply with these terms. 